\title{
GENNEROS DE TEXTO: UMA VIA DE ABORDAGEM DAS VARIAÇÕES EM LÍNGUA ESCRITA
}

\author{
Irandé Costa Antunes \\ Programa de Pós-Graduação em Letras \\ Universidade Federal de Alagoas
}

\section{INTRODUÇÃO}

A questão da variação lingüística tem contemplado as múltiplas possibilidades de a língua realizar-se, atendendo a diferenças de lugar, do meio social ou da situação sociocultural em que a atividade verbal ocorre. Tais possibilidades de variação, embora tenham sido preferencialmente consideradas em relação à língua oral, aplicam-se igualmente ao uso da modalidade escrita da língua.

Em qualquer dos casos, a consideração do fenômeno da variação lingüística implica, necessariamente, a inclusão dos muitos fatores pragmáticos envolvidos na produção e na recepção da interação lingüística. Ou seja, se a realização da língua comporta variações é por determinação de elementos exteriores a ela, elementos constituintes da situação social em que a atividade verbal se insere, tais como o estatuto social dos interlocutores e o tipo de relação que se estabelece entre eles, para citar apenas dois desses fatores.

Tomando como parâmetro a língua escrita, os diferentes gêneros de textos constituem um campo privilegiado para o entendimento funcional dessas possibilidades de variação da língua escrita.

\section{LÍNGUA ESCRITA, VARIAÇÃO E GÊNEROS TEXTUAIS}

Dentro das semelhanças existentes entre as modalidades oral e escrita da língua uma, sem dúvida, reside na constatação de que, tal como na oralidade, os textos escritos também admitem variações. Ou seja, a eles também 
se podem aplicar as palavras de Dubois et alli (1989), quando definem a variação como um fenômeno pelo qual, no cotidiano da atuação verbal, uma língua determinada nunca é, numa época, num lugar e num grupo social determinados, idêntica ao que foi em outra época, em outro lugar e em outro grupo social (p. 609).

A aceitação desse principio implica que se esteja considerando a língua escrita para além do quadro estritamente frástico e, assim, como um sistema que somente se plenifica na atualização de atos verbais, estes, por sua vez, partes significativas da atuação mais ampla das pessoas no meio social em que vivem. Assim, os textos escritos são formas verbais dessa atuação social, ou são, pelo menos, componentes verbais dessas atuações. De maneira que escrever um texto é, concomitantemente, inserir-se num contexto qualquer de atuação social e pontuar nesse contexto uma forma particular de interação verbal. Por essa razão é que, além das determinações do sistema lingüistico, a produção e recepção de textos estão sujeitas também às determinações dos contextos socioculturais em que essas atividades acontecem.

Ora, sabemos que as formas de atuação social que as pessoas empreendem são múltiplas e diferenciadas, pois resultam de situações também múltiplas e diferenciadas, no tempo e no espaço, ou respondem a intenções e objetivos vários. A própria singularidade inscrita na determinação da natureza humana conduz à previsibilidade da variação, da dissemelhança, da heterogeneidade. da instabilidade. A história da humanidade se confunde com a história da mudança, da ininterrupta quebra do estabelecido pela introdução do novo, nesse contexto, já não inesperado.

Toma-se, portanto, como definição o principio de que a lingua varia, também na sua modalidade escrita, em decorrência da imposição de adequar-se às diferentes situações de uso em que se insere. As linguas existem para essas situações, em função de suas solicitações interacionais.

Werlich (1976) adverte que os textos estão sempre especificamente em correlação com determinados fatores 
contextuais presentes a uma situação de comunicação. Tais fatores constituem o que esse autor chama de "o foco contextual de um texto". É por isso que cada tipo de texto se caracteriza por determinadas marcas lingüisticas de superfície (como, por exemplo, o emprego de certos tempos verbais - o imperfeito, para o tipo descritivo, o imperativo, para o tipo instrutivo etc. (cf. Canvat, 1996, p.13)).

Também em decorrência desse foco contextual é que um texto informativo contém poucas ocorrências de marcadores temporais, uma vez que o próprio fluxo cronológico em que as informações são apresentadas providencia o estabelecimento da seqüência temporal requerida para o desenvolvimento do texto. O tipo argumentativo, no entanto, normalmente, requisita um número maior e mais variado de seqüenciadores, uma vez que supõe formas de desenvolvimento criadas a partir do plano que, em cada caso, a inter-relação entre conceitos e fatos sugere ou a orientação argumentativa, pretendida pelo texto, indica (cf. Antunes, 1996).

Dentro dessa perspectiva da variação dos textos em função dos contextos em que circulam, a Lingüistica de orientação pragmática tem proposto e desenvolvido a categoria de "gêneros textuais", na pretensão de caracterizar as especificidades das manifestações culturais concernentes ao uso da lingua e de facilitar o tratamento cognitivo desse uso, seja oral, seja escrito.

Tais gêneros têm sido definidos como constitutivos da situação (cf. Dolz \& Schneuwly, 1996, p. 57). Dessa forma, essa categoria soma-se a outra dos "tipos de texto", porém amplia-a, no sentido de que é parte da situação, além de definir os conteúdos, a superestrutura e as configurações específicas, próprias do funcionamento desses tipos. Por isso, se tem referido a esses gêneros também como "classes de textos", conforme correspondem à multiplicidade dos objetivos sociais de interação.

Uma visão preliminar - e inteiramente arriscada - do conjunto dessas classes de textos poderia ser dada através do quadro que apresento a seguir. 
Quadro 1. Hipóteses de classificação da diversidade dos textos escritos

\begin{tabular}{|l|l|l||}
\hline 1. Quanto ao tipo: & $\begin{array}{l}\text { 2. Quanto às } \\
\text { funções: }\end{array}$ & $\begin{array}{l}\text { 3. Quanto ao } \\
\text { registro: }\end{array}$ \\
\hline 1.1. o narrativo & 2.1. o apelativo & 3.1. o informal \\
\hline 1.2. o descritivo & 2.2. o informativo & 3.2. o formal \\
\hline 1.3. o expositivo & 2.3. o expressivo & \\
\hline 1.4. o argumentativo & 2.4. o poético & \\
\hline 1.5. o instrutivo & 2.5. o metalingüístico & \\
\hline & 2.6. o fático & \\
\hline
\end{tabular}

\begin{tabular}{|l|l|l||}
\hline \hline \multicolumn{3}{|l|}{ Quanto à diversidade de gêneros ou "classes de textos": } \\
\hline bula & receita culinária & instrução de uso \\
\hline diário & (auto)biografia & $\begin{array}{l}\text { projeto / ensaio / } \\
\text { artigo acadêmico } \\
\text { monografia / } \\
\text { dissertação / tese }\end{array}$ \\
\hline editorial & comentário & lição didática \\
\hline $\begin{array}{l}\text { declaração /atestado } \\
\text { parecer }\end{array}$ & $\begin{array}{l}\text { regulamento código } \\
\text { estatuto }\end{array}$ & $\begin{array}{l}\text { ata / registro de } \\
\text { ocorrência } \\
\text { relatório } \\
\text { curriculum vitae }\end{array}$ \\
\hline entrevista & $\begin{array}{l}\text { contrato } \\
\text { escritura }\end{array}$ & $\begin{array}{l}\text { requerimento } \\
\text { procuração }\end{array}$ \\
\hline $\begin{array}{l}\text { oficio/ portaria / } \\
\text { circular }\end{array}$ & $\begin{array}{l}\text { carta } \\
\text { bilhete }\end{array}$ & $\begin{array}{l}\text { convite } \\
\text { convocação }\end{array}$ \\
\hline oração / prece & resumo & esquema \\
\hline prognóstico do tempo & laudo médico & boletim médico \\
\hline anúncio & mensagem publicitária & $\begin{array}{l}\text { aviso } \\
\text { nota de } \\
\text { esclarecimento }\end{array}$ \\
\hline Sermão / homilia & saudação & $\begin{array}{l}\text { teste / questionário / } \\
\text { formulário }\end{array}$ \\
\hline $\begin{array}{l}\text { anedota } \\
\text { adivinhação }\end{array}$ & novela/ romance & conto / fábula \\
\hline notícia & epitáfio & roteiro turístico \\
\hline reportagem & crônica & programação \\
\hline poema & provérbio & $\begin{array}{l}\text { nota de } \\
\text { esclarecimento }\end{array}$ \\
\hline nota de falecimento \\
\hline recensão critica & edital & \\
\hline
\end{tabular}


Como se pode ver, a distribuição dos textos por classes resulta mais específica, mais diferenciada do que as outras por tipo ou por função.

Parece relevante observar que o levantamento exaustivo de todas as classes de textos escritos em circulação nas sociedades letradas constitui uma tarefa muitíssimo complexa, dada, já se sabe, à quase ilimitada possibilidade de variação dos contextos de ocorrência desses textos. Como disse, o que ora apresento é um esquema provisório, na tentativa de deixar a questão um pouco mais organizada, admitindo claramente que esse esquema deve receber emendas e alterações. Complemento esse quadro com elementos de outras tipologias, já sedimentadas na literatura lingüística (cf. Werlich, 1976; Adam, 1985; 1987b; Bronckart et al. 1985, Petitjean, 1989).

Apesar de seus limites, o quadro apresentado permite estabelecer um marco dentro do qual os textos se definem e se delimitam frente a outros, individualizando-se como representativos de uma classe particular. Evidencia, por outro lado, o aspecto da variedade assumida pelos textos escritos e posta, aqui, em relevo.

Há um aspecto, contudo, que parece contrariar esse princípio da diferença. $\mathrm{Na}$ verdade, a variedade constatada acontece nos limites impostos pelas convenções estabelecias nas já mencionadas condições de funcionamento dos textos. Ou seja, as diferentes classes de texto prevêem um conjunto regular de formas e de padrões de ocorrência, de modo que essas classes são reconhecidas como classes prototípicas, convencionalmente estabelecidas e socialmente esperadas. Constituem, assim, padrões historicamente sedimentados e, como tal, orientam a atividade textual, pois "todo texto se apresenta, a um tempo, típico e singular" (cf. Bronckart, 1987, p. 45). É também sob esta condição de típico que se dá a demarcação de seu arranjo seqüencial, incluindo "os elementos obrigatórios", "os elementos opcionais", "os elementos iterativos" (cf. Hasan, 1979; Halliday \& Hasan 1989) - bem como a delimitação de seu sentido global (cf. van Dijk, 1984; Adam, 1985; 1987a; Guimarães, 1985). É evidente que tais previsões podem ser quebradas, na dependência da 
intenção do sujeito de, violando-as, conseguir um efeito comunicativo qualquer. $\dot{E}$ evidente, ainda, que esses protótipos podem alterar-se com o tempo ou podem aparecer novos modelos, devido a novas exigências sociais da interação verbal.

O paradoxo da variação e da realização prototípica dos textos é apenas o reflexo da natureza mesma da língua, definida como, a um tempo, sujeita à tradição e à ação livre da sociedade. Se, por um lado, como admite Saussure (1973, p. $90)$, uma língua é "radicalmente incapaz de se defender" dos fatores que, constantemente, a deslocam ( $p .90$ ), por outro, a solidariedade com 0 passado restringe e controla esse inevitável deslocamento (p. 88).

As classes de textos põem em evidência a pertinência desse princípio: são multiformes, em atendimento à variação dos fatores contextuais que incluem e, por outro lado, são prototípicas atendendo à natureza convencional das instituições sociais a que servem.

\section{LÍNGUA ESCRITA, VARIAÇÃO, GÊNEROS DE TEXTO E ENSINO}

Deixando de lado a análise de como a escola tem providenciado o ensino da língua escrita, e a denúncia já tão disseminada do fracasso de seus resultados, concentro-me, nesse instante, em anunciar alguns pontos acerca do que poderia ser feito, em termos de um ensino escolar mais eficaz da lingua escrita.

3.1 O ensino da língua escrita deveria privilegiar o ensino pela leitura, produção e análise - de textos escritos, concretamente, o ensino das diferentes classes de texto, de cuja circulação social somos agentes e testemunhas. Os critérios de escolha dessas classes de textos, adaptados a cada estágio da escolaridade, poderiam advir da observação das ocorrências comunicativas atuais, ou seja, daquilo que, de fato, se usa nas transações sociais. A diversidade de textos requisitada pela diversificação de seus usos e pela importância crescente que se tem atribuido à escrita são justificativas relevantes para que se promova a competência dos alunos na 
produção e na recepção de textos adequados e relevantes socialmente.

3.2 A superestrutura típica de cada classe de texto, conforme está legitimada pelas convenções sociais, constituiria um dos pontos centrais desse estudo. Dessa forma, a escrita de frases ou a escrita de textos sem a referência de suas condições de recepção dariam lugar à escrita de textos com feições particulares, situadas, com planos de desenvolvimento, de progressão, de ordenação dos diferentes blocos que remetem para classes particulares de texto, sem se comprometer, por isso, a criatividade e a heterogeneidade dos sujeitos que escrevem.

3.3 A gramática da lingua, um quebra-cabeças na vida de grande parte dos professores, seria a gramática para essas classes de textos, ou a gramática dessas classes de textos, em função do que se poderia estabelecer, com mais precisão e muito mais consistência, o alcance das regras $e$, principalmente, o impulso para se minimizar o estudo das nomenclaturas e das irrelevâncias classificatórias. Seria uma gramática voltada para os diferentes contextos sociais de uso da língua, para os diferentes modos de interação verbal, lugar onde a lingua, de fato, cubra inteira relevância. Seria uma gramática mais pontualizada e mais próxima das operações que as pessoas realizam quando usam a lingua em situações concretas de comunicação. Pareceria irrelevante, inócua, inalcansável?

3.4 Na prática do ensino das classes de textos, o relevo havia de contemplar, destacar e explicitar aquele aspecto da variabilidade e da prototipicidade dos textos, pondo-se em correlação a tensão natural entre o poder de escolha do sujeito e as injunções sociais que presidem o uso da língua. Dessa forma, o sujeito se via como elemento decisor, atuante na sua criação individual e, ao mesmo tempo, partícipe de uma comunidade que vivencia, também, a solidariedade lingüística. Ou, ainda, como autor singular do seu texto e vinculado à ampla e irrestrita intertextualidade dos usos sociais da língua.

3.5 Somente pela concentração nas classes de texto se poderia, com pertinência, identificar o destinatário do texto (ou 
os destinatários, se fosse o caso) em seu papel social particular, para levá-lo em conta na dosagem da informação veiculada, na antecipação das posições contrárias e, mais pontualmente, na escolha sintático-semântica das unidades lingüísticas. Outro aspecto favorecido seria a identificação do lugar e do momento institucional em que o texto será lido. Essa previsão constitui um dos parâmetros de seleção dos elementos disponíveis nos paradigmas da textualidade.

O mito da uniformidade lingüística e a compreensão ingênua de uma escrita única, inalteravelmente padronizada, tão comum ao simplismo abusivo da prática escolar, seriam radicalmente abalados pelo confronto com a diversidade das diferentes classes de textos. Se a predominância de um ensino da metalinguagem gramatical deixou a idéia de uma língua oral inalterável, muito mais ainda aconteceu em relação à língua escrita, vista, quase sempre, na sua realização formal, literária ou, pior, ainda, como exercício de uma "redação" sem intenção, sem finalidade comunicativa, sem leitor, sem contexto. Exaurindo-se apenas na finalidade do treino.

Até quando havemos de esperar por um ensino da língua que, em cada momento, estimule a compreensão, a fluência, o intercâmbio, a atuação verbal como forma de participação nossa na construção de um mundo, inclusive lingüisticamente, mais justo e mais humano? Até quando havemos de conviver com um ensino irrelevante, excludente, desencorajador, marginal a quase tudo que dá sentido à grandiosa aventura da vida humana?

\section{REFERÊNCIAS BIBLIOGRÁFICAS}

ANTUNES, Irandé Costa. Aspectos da coesão do texto - uma análise em editoriais jornalísticos. Recife: Editora da UFPE, 1996.

ADAM, Jean-Michel. Quels types de texte? Le Français dans le monde. n. 192, p. 39-43, 1985.

ADAM, Jean-Michel. Textualité et séquencialité - l'exemple de la description. Langue Française, n. 74, p. 51-72, 1987 a. 
ADAM, Jean-Michel. Types de séquences textuelles élémentaires. Pratiques. n. 56, p. 54-79, $1987 \mathrm{~b}$.

BERNARDEZ, Enrique (Ed.). Lingüistica de Texto. Madrid: Arco/Libros, 1987.

BRONCKART, Jean-Paul. Interactions, discours, signification. Langue Française. n. 74, p. 29-50, 1987.

CANVAT, Karl. Types de textes et genres textuels problématique et enjeux. Enjeux - Revue de didatique du français. CEDOCEF , n. 37/38, p. 5-47, mars/juin 1996.

DIJK, Teun Adrianus van. Texto y contexto. Madrid: Cátedra, 1984.

DOLZ, Joaquim; SCHNEUWLY, Bernard. Genres et progression en expression orale et écrite. Élements de réflexions à propos d'une expérience romande. Enjeux Revue de didatique du français. CEDOCEF, n. 37/38, p. 49-75, mars/juin 1996.

DUBOIS et alli. Dicionário de Lingüística. São Paulo: Cultrix, 1989.

GUIMARÃES, Eduardo Junqueira. Polifonia e tipologia textual. In: FÁVERO \& PASCHOAL (Orgs.). Lingüística Textual : texto e leitura. São Paulo: Educ, 1985. p. 75-88.

HALLIDAY, Michael A. K.; HASAN, Ruqaiya. Language Context, and text - aspects of language in a social-semiotic perspective. 2. ed. Oxford:University Press, 1989.

HASAN, Ruqaiya. On the notion of text. In: PETÖFI (Ed.). Text vs sentence - basic questions os text linguistics. Hamburg: Helmut Busque, 1979. p. 369-390.

PETITJEAN, A. Les typologies textuelles. Pratiques, n. 62, p. 86-125, 1989.

SAUSSURE, Ferdinand. Curso de Lingüística Geral. 5 ed. São Paulo: Cultrix, 1973.

WERLICH, E. A Text Grammar of English. Heideberg, 1976. 